\title{
Sumari
}

Papers. Revista de Sociologia

Juliol-setembre 2010, vol. 95, núm. 3, p. 553-873

ISSN 0210-2862 (imprès)

http://ddd.uab.cat/record/35

http://ojs.uab.cat/index.php/papers

ISSN 2013-9004 (en línia)

557-561 Presentación. El desarrollo de la familia en España desde una perspectiva demográfica

\section{Articles Monogràfic}

565-583 Cortina, Clara (Consejo Superior de Investigaciones Científicas); Cabré, Anna (Centre d'Estudis Demogràfics)

Las uniones homosexuales en España. Una caracterización sociodemográfica a partir del censo de 2001. Papers, 2010, vol. 95, núm. 3, p. 565-583.

Palabras clave: uniones homosexuales, censo de 2001, homogamia, matrimonio.

585-608 Esteve, Albert (Universitat Autònoma de Barcelona); Cortina, Clara (Consejo Superior de Investigaciones Científicas)

Expansión educativa e inmigración internacional en España: cambios en la formación de la pareja. Papers, 2010, vol. 95, núm. 3, p. 585-608.

Palabras clave: homogamia educativa, población extranjera, nivel de instrucción, nacionalidad, matrimonio, España, censo de 2001.

609-632 Simó, Carles (Universitat de València); Solsona, Montse (Universitat Autònoma de Barcelona)

El registro estadístico de las rupturas de unión en España. Evaluación e ideas para avanzar desde la demografía. Papers, 2010, vol. 95, núm. 3, p. 609-632.

Palabras clave: ruptura de unión, divorcio, registro estadístico, fuentes demográficas. 
633-653 Nicolau, Roser; Devolder, Daniel; Panareda, Eva (Universitat Autònoma de Barcelona)

La modernización de los comportamientos de fecundidad en España durante el siglo XX. Un estudio a nivel provincial para las generaciones nacidas en la primera mitad del siglo XX. Papers, 2010, vol. 95, núm. 3, p. 633-653.

Palabras clave: fecundidad, generación, rango de nacimiento, control de la fecundidad, probabilidad de agrandamiento, España, provincias, siglo XX.

655-672 Módenes, Juan A.; López-Colás, Julián (Universitat Autònoma de Barcelona) Población y vivienda en España: el sistema residencial a la luz del censo de 2001. Papers, 2010, vol. 95, núm. 3, p. 655-672.

Palabras clave: población, vivienda, España, censos.

673-700 Alustiza Galarza, Ainhoa (Centre d'Estudis Demogràfics); Pérez Díaz, Julio (Instituto de Economía, Geografía y Demografía) Familia, envejecimiento y discapacidad en España. Papers, 2010, vol. 95, núm. 3, p. 673-700.

Palabras clave: familia, edad, envejecimiento, salud, discapacidad, España.

701-729 Recaño Valverde, Joaquín (Universitat Autònoma de Barcelona)

Las migraciones internas de retorno en España. De la óptica individual a la dimensión familiar. Papers, 2010, vol. 95, núm. 3, p. 701-729.

Palabras clave: migración de retorno, España, migración interna, óptica de análisis individual, perspectiva familiar, hogares, género.

731-754 Domingo, Andreu (Universitat Autònoma de Barcelona); Bayona, Jordi (Universitat de Barcelona)

Los hogares de la población de nacionalidad extranjera en España en el año 2001. Papers, 2010, vol. 95, núm. 3, p. 731-754.

Palabras clave: población de nacionalidad extranjera, familia, estructura del hogar, censo de 2001, España.

\section{Notes d'investigació Monogràfic}

757-777 Miret Gamundi, Pau (Universitat Autònoma de Barcelona)

Emancipación juvenil a través de la formación de la pareja. Una comparación entre los censos de 1991 y de 2001. Papers, 2010, vol. 95, núm. 3, p. 757-777.

Palabras clave: modelos de emancipación, familia, parejas, España. 


\section{Articles Miscelànic}

781-801 Huete, Raquel; Mantecón, Alejandro (Universidad de Alicante) Los límites entre el turismo y la migración residencial. Una tipología. Papers, 2010, vol. 95, núm. 3, p. 781-801.

Palabras clave: movilidad internacional, Mediterráneo, turismo residencial, jubilados, sociología.

803-831 Cavalca, Guido (Università di Milano-Bicocca)

Las madres solas en contextos urbanos europeos. Milán y Berlín: puntos en común y divergencias en los procesos de empobrecimiento. Papers, 2010, vol. 95, núm. 3, p. 803-831.

Palabras clave: empobrecimiento, madres solas, contextos urbanos, análisis dinámico.

833-855 Moreno Colom, Sara (Universitat Autònoma de Barcelona)

El temps dins la sociologia: entre l'oblit i l'omnipresència analítica. Papers, 2010, vol. 95, núm. 3, p. 833-855.

Paraules clau: temps, sociologia, epistemologia.

\section{Notes d'investigació Miscelànic}

859-870 Sarrible, Graciela (Universitat de Barcelona)

Fecundidad diferencial de distintas subpoblaciones de mujeres en España: una diferencia no tan grande. Papers, 2010, vol. 95, núm. 3, p. $859-870$.

Palabras clave: fecundidad diferencial, España, mujeres extranjeras.

\section{Ressenyes}

871-873 García del León, María Antonia; Fernández-Fígares, María Dolores. Antropólogas, politólogas y sociólogas. Género, biografía y ciencias sociales (Juana María Ruiloba Núnez).

Normes de publicació a Papers. Revista de Sociologia Normas de publicación en Papers. Revista de Sociologia Guidelines for publication in Papers. Revista de Sociologia 